\title{
Modelo de realidad virtual del centro histórico del Distrito Central basado en análisis espacial con sistemas de información geográfica
}

Eduardo Moreno Segura*

\section{RESUMEN}

El presente proyecto es un producto derivado de los análisis hechos utilizando el SIG para la Gestión de Centros Históricos desarrollado como iniciativa del Observatorio Astronómico Centroamericano de Suyapa de la UNAH. El propósito de este producto es mostrar mediante modelado 3D, recorridos de realidad virtual interactivos, referente al estado de conservación arquitectónico y rotulación de las principales calles y avenidas del Centro Histórico del Distrito Central que sirva además para proponer y promover proyectos educativos y turísticos así como de mejoramiento y desarrollo que tengan dentro de su área de estudio el Centro Histórico de Tegucigalpa y Comayagüela, con miras a contribuir al proceso de gestión de los mismos tomando en cuenta su trascendencia histórica.

La visualización fotorrealística 3D se aplica a áreas como la arquitectura, arqueología, cartografía, ingeniería civil, medicina entre otras, y como herramienta de investigación, conservación, gestión y divulgación de patrimonio histórico y turístico. Tal es el caso de los modelos generados en este proyecto, los cuales pueden ser usados por técnicos y restauradores con el fin de hacer estudios, análisis o futuras predicciones sobre planes de actuación.

Además este modelo 3D o maqueta virtual del centro histórico de Tegucigalpa permitirá al ciudadano de la calle comprender el presente comparando el pasado, y conocer el futuro de su ciudad.

Palabras Clave: Centro Histórico, Realidad Virtual, Modelo 3D, Sistemas de Información Geográfica

\footnotetext{
* Eduardo Moreno Segura, eddmorse7@hotmail.com

Facultad de Ciencias Espaciales, Laboratorio de Percepción Remota, Observatorio Astronómico

Centroamericano de Suyapa, Universidad Nacional Autónoma de Honduras.
} 


\section{ABSTRACT}

This project is a byproduct of the analysis done using GIS for the Management of Historic Centers developed as an initiative of the Central American Astronomical Observatory of Suyapa UNAH. The purpose of this product is to show through 3D modeling, interactive virtual reality tours, covering the state of architectural preservation and labeling of the main streets and avenues of the Historic Center of the Central District that also serves to propose and promote educational and tourist projects as well as improvement and development that have within their area of study the historical center of Tegucigalpa and Comayagüela, with a view to contributing to the process of administering them taking into account its historical significance.

3D photorealistic visualization is applied to areas such as architecture, archeology, mapping, civil engineering, medicine among others, and as a tool for research, conservation, management and dissemination of heritage and tourist. Such is the case of models generated in this project, which can be used by technicians and restorers in order to carry out studies, analysis or predictions about future action plans.

Furthermore this model 3D virtual model of the historic center of Tegucigalpa allow the citizen in the street understand the present by comparing the past and know the future of their city.

Key words: Historical Center, Virtual Reality, 3D Model-GIS 


\section{INTRODUCCIÓN}

Actualmente en nuestro país nos encontramos con el problema de que la forma de concientización y educación para el conocimiento y la conservación del patrimonio histórico y cultural de una ciudad, no cuenta con un modelo 3D de realidad virtual enlazado a un sistema de información geográfica que permita además de representar el estado histórico y las propuesta de conservación y desarrollo arquitectónico, actualizar los datos para realizar los análisis geoespaciales y promover los resultados.

La investigación es hoy un importante activo capaz de hacer avanzar el desarrollo de sistemas que integran las tecnologías de información y de visualización en 3D aplicadas al ámbito de variedad de disciplinas como son la arquitectura, la historia, la planificación urbana, ordenamiento territorial o simplemente aplicadas al conocimiento de la ciudad.

Con la aparición de tecnologías de realidad virtual compatibles con las de SIG, junto con el avance en las vías rápidas de comunicación de gran capacidad, se está proporcionando a los investigadores la infraestructura fundamental para comenzar a construir ciudades virtuales que pueden recrear un entorno interactivo de simulación y análisis de los lugares urbanos con auténtico realismo, que a la vez pueden integrar todo el conjunto de parámetros medioambientales (físicos sociales y económicos) que requiere la planificación urbana.

Considerando lo anterior, con el proyecto "Modelo de Realidad Virtual del Centro Histórico del Distrito Central basado en Análisis Espacial con Sistemas de Información Geográfica", construimos un modelo cuyas características ayudarán a optimizar las consultas a las investigaciones y proyectos desarrollados para el ordenamiento territorial, la gestión, conservación y desarrollo del centro histórico, así como de verlos proyectados de una forma comprensible e interactiva, dando paso a una buena promoción y divulgación educativa, en diferentes niveles del conocimiento.

Además dicho proyecto tiene el propósito de mostrar recorridos de realidad virtual 3D interactivos, que revelen el estado de conservación arquitectónica de los edificios y estructuras de las principales calles y avenidas del Centro Histórico del Distrito Central de Honduras y para ello se describen en este articulo la metodología para el desarrollo del modelo así como el análisis derivado de los productos. 


\section{METODOLOGÍA}

Basado en el propósito de crear un modelo de realidad virtual del Centro Histórico del Distrito Central se desarrolló una metodología que comprendió los siguientes aspectos:

\section{Identificación y selección del área de estudio}

Para la zona de estudio y aplicación del proyecto se seleccionó un sector representativo ya sea por su variedad tipológica de edificios y su trascendencia histórica dentro del área definida como Casco Histórico del Distrito Central según Acuerdo No. 527, del 20 diciembre de 1994, donde se declara Monumento Nacional al Casco Histórico del Distrito Central y zonas aledañas (Diario Oficial de Honduras, LAGACETA, 1995), ver figura 1.

\section{Figura 1. Centro Histórico del Distrito Central}

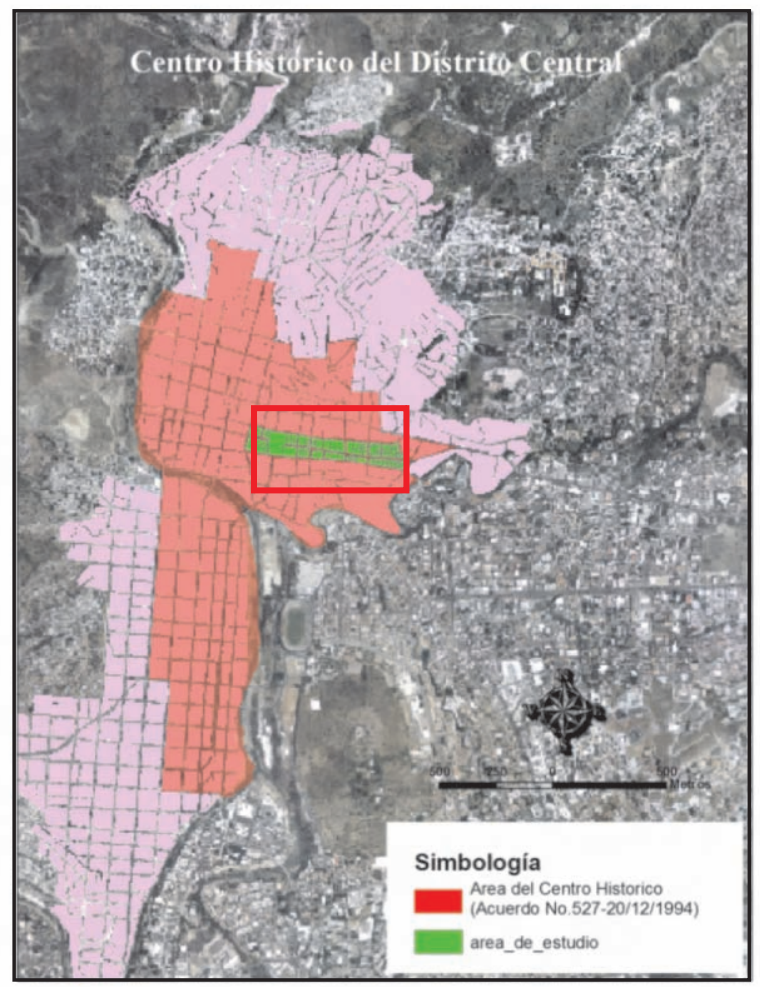

El área de estudio seleccionada comprende las manzanas que se encuentran a lo 
largo de la Avenida Paz Barahona. Estas manzanas de acuerdo a su nomenclatura en el catastro municipal del Distrito Central son: $73,74,75,76,77,78,81,82,83$, 84,85 en el Sector 01 (ver Figura 2).

Figura 2. Área de estudio (Avenida Paz Barahona)

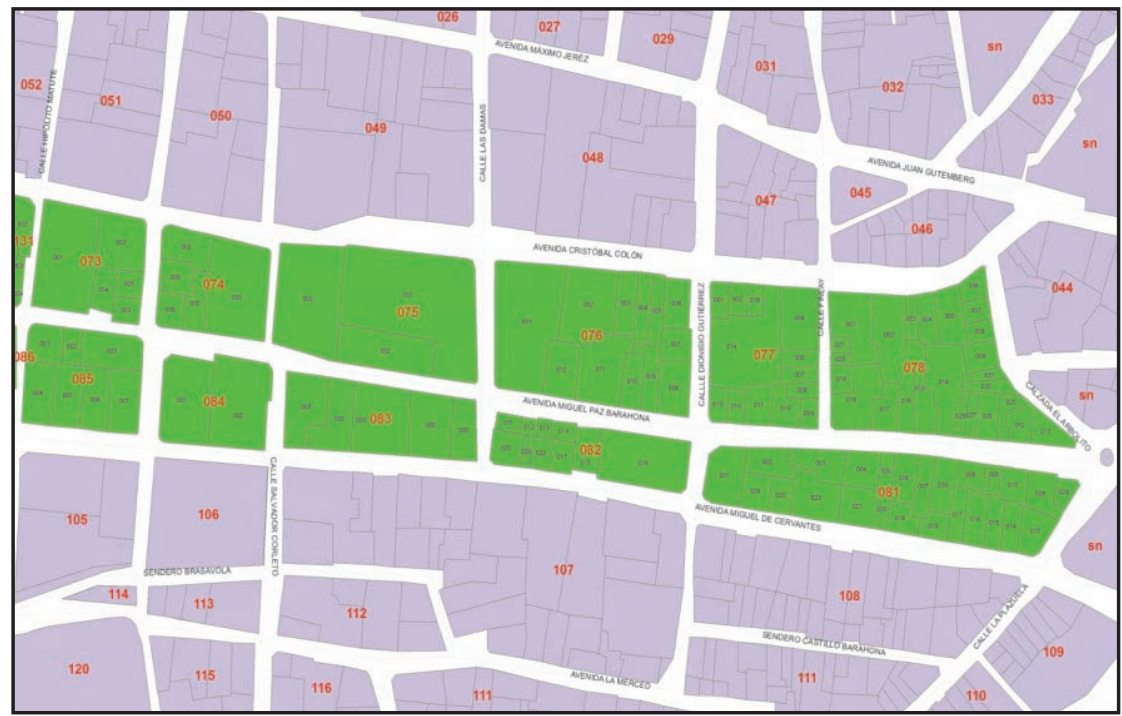

Recolección de datos (cartografía y documentación fotográfica de fachadas y planos)

La topografía de la zona, limites geográfico y planimetría así como la cartografía base utilizada en el proyecto, parte de la existencia de la información procesada en el SIG para la Gestión de Centros Históricos (2006) en donde ya se ha logrado la estandarización y clasificación de los datos en parámetros de:

- Calidad de los datos: precisión, fiabilidad.

- Organización de los datos espaciales: vector, raster.

- Referencia espacial: proyección, datum, sistemas de coordenadas.

- Entidad y atributos: información acerca de entidades, atributos, dominio de valores de los atributos.

- Distribución: distribuidor, formatos, precio, otros.

- Referencia de los metadatos: nivel de actualización, institución o persona responsable, otros. 
Además se realizó un levantamiento de campo y documentación fotográfica actual de las fachadas en cada una de las edificaciones comprendidas en la zona de estudio.

\section{Procesado y limpieza digital de imágenes}

Las fotografías de las fachadas de cada edificación proveerán de la textura necesaria para cada modelo y así dar la sensación de realismo; es por eso que antes de esto se le dio a cada fotografía un proceso de limpieza digital de cualquier elemento que dificulte la visibilidad y apreciación integra y clara de la fachada, además de generar mosaicos de fotografías que completen la apreciación total de un edificio. Esto se logró con un programa de edición de imágenes (Adobe Photoshop).

Figura 3. Fotografía con limpieza digital de sombras

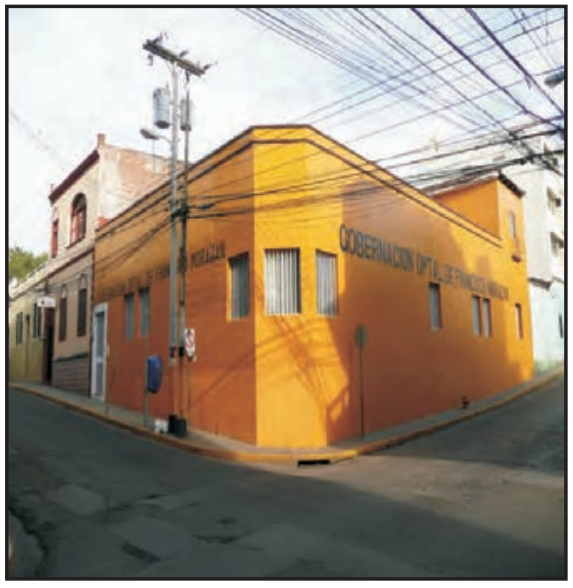

Fotografía original

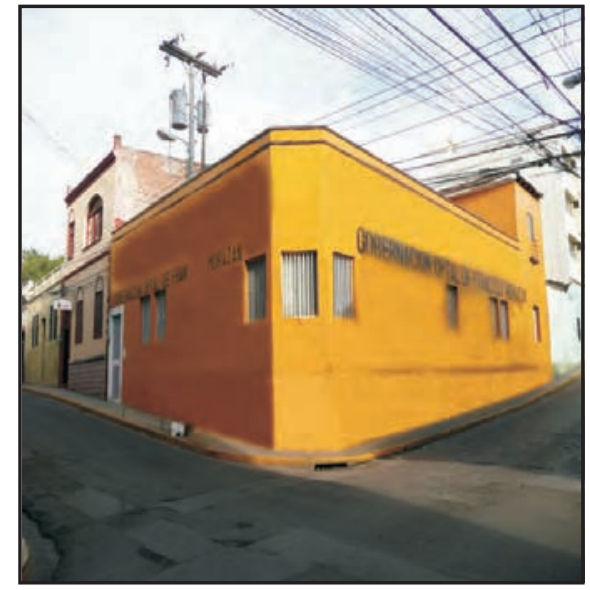

Fotografía con limpieza digital

\section{Digitalización de fachadas en $2 \mathrm{~d}$ (modelo digital de predios urbanos)}

Cada una de las fachadas de la edificaciones seleccionadas fueron digitalizadas de forma precisa, considerando la escala, componentes y detalles arquitectónicos, provistos por las fotografías y los planos.

Esto se realizó haciendo uso de un programa de diseño asistido por computadora (CAD) y utilizando como base cartográfica los predios urbanos del centro histórico del catastro municipal, el cual proveyó de referencia geoespacial al proceso de digitalización de fachadas. 
Figura 4. Modelo digital de predios urbanos
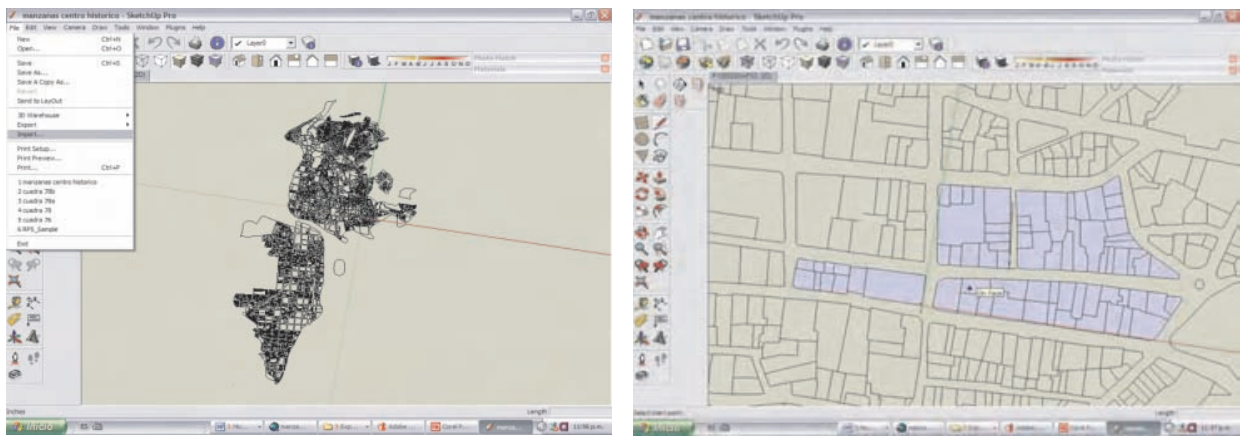

En este proceso la visualización de los datos digitalizados se presenta de forma bidimensional (2d) por lo que aun no se aprecia la volumetría de los edificios (ver figura 4).

\section{Generación de volúmenes de edificaciones en 3d}

Se generó el volumen de cada edificación a partir de la fotografía, con el proceso llamado fotografía adaptada (software Google Sketchup 6.0), que permite adaptar el modelo digital a la misma perspectiva visual de la fotografía, haciendo coincidir sus puntos de fuga. Una vez logrado esto, es posible escalar la fotografía al modelo digital (2d) de la fachada, generar volúmenes a partir de la misma fotografía dando proporción y forma a los elementos que constituyen la fachada del edificio y mostrar su aspecto tridimensional (ver figura 5).

En este proceso las técnicas fotogramétricas se han utilizado para dotar a los elementos e imágenes del tamaño exacto. Por lo tanto, la impresión visual es exactamente la misma que el usuario captaría en la zona real.

Figura 5. Proceso de generación de volúmenes $3 d$

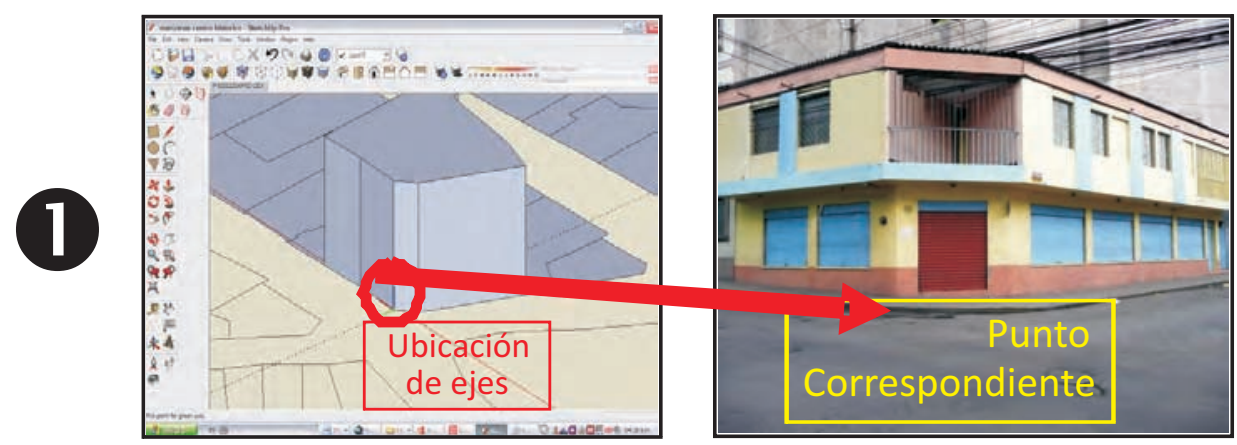



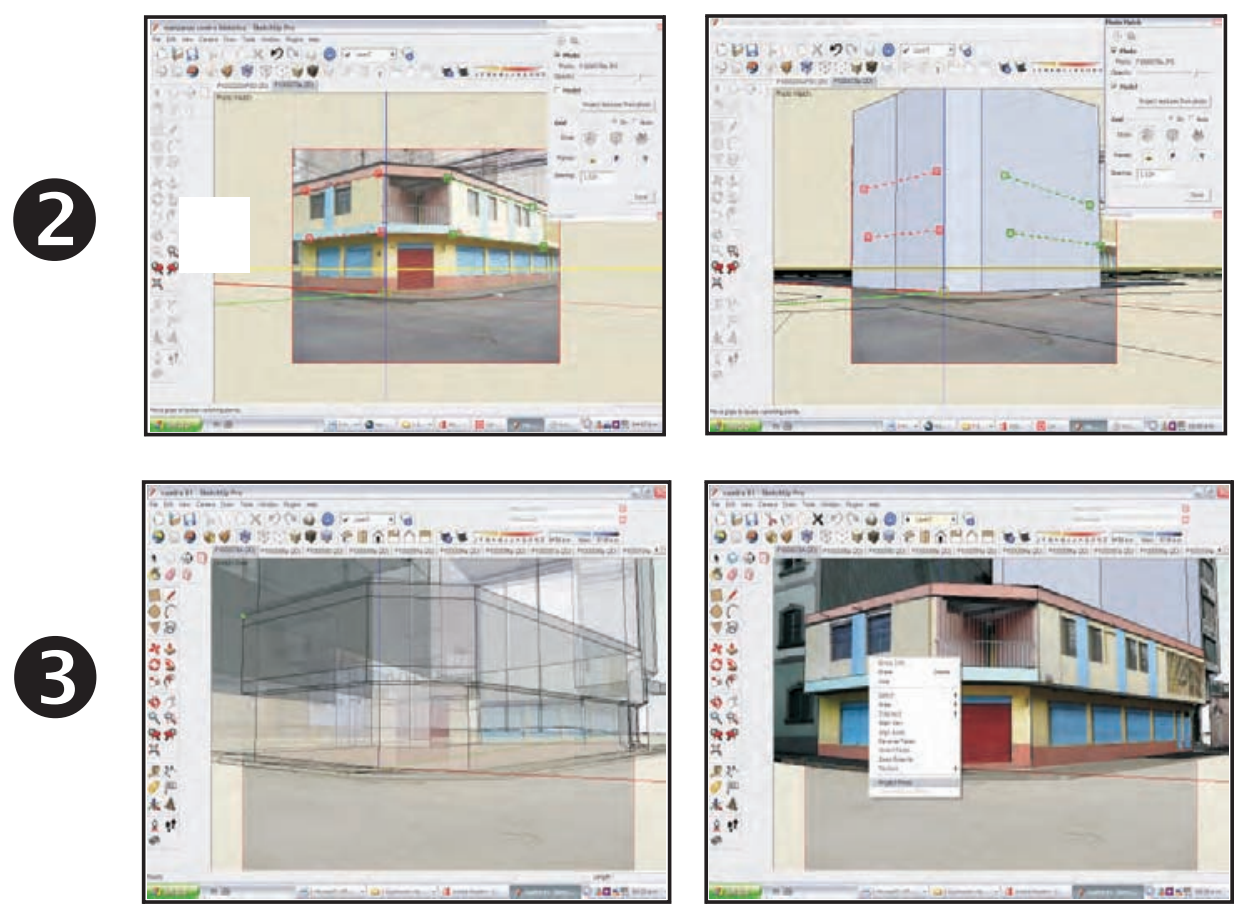

1. Ubicación de ejes y punto de correspondencia entre el modelo digital y la fotografía

2. Ajuste de los puntos de fuga del modelo para que coincidan con los de la fotografía.

3. Trazado de esquema 3D del edificio y proyección de textura.

\section{Renderizado de materiales y texturas fotográficas rectificadas}

Este proceso se lleva a cabo cuando los materiales definidos por su color y propiedades radio métricas, así como las texturas fotográficas previamente rectificadas son proyectadas sobre la geometría del modelo 3D, y consiste en suavizar las aristas que por geometría del modelo se notan mucho; esto es para dar un mayor realismo al modelo y acabado profesional. En la Figura 6 se muestra una manzana completa renderizada desde diferentes ángulos. 
Figura 6. Renderizado de escenas en una manzana
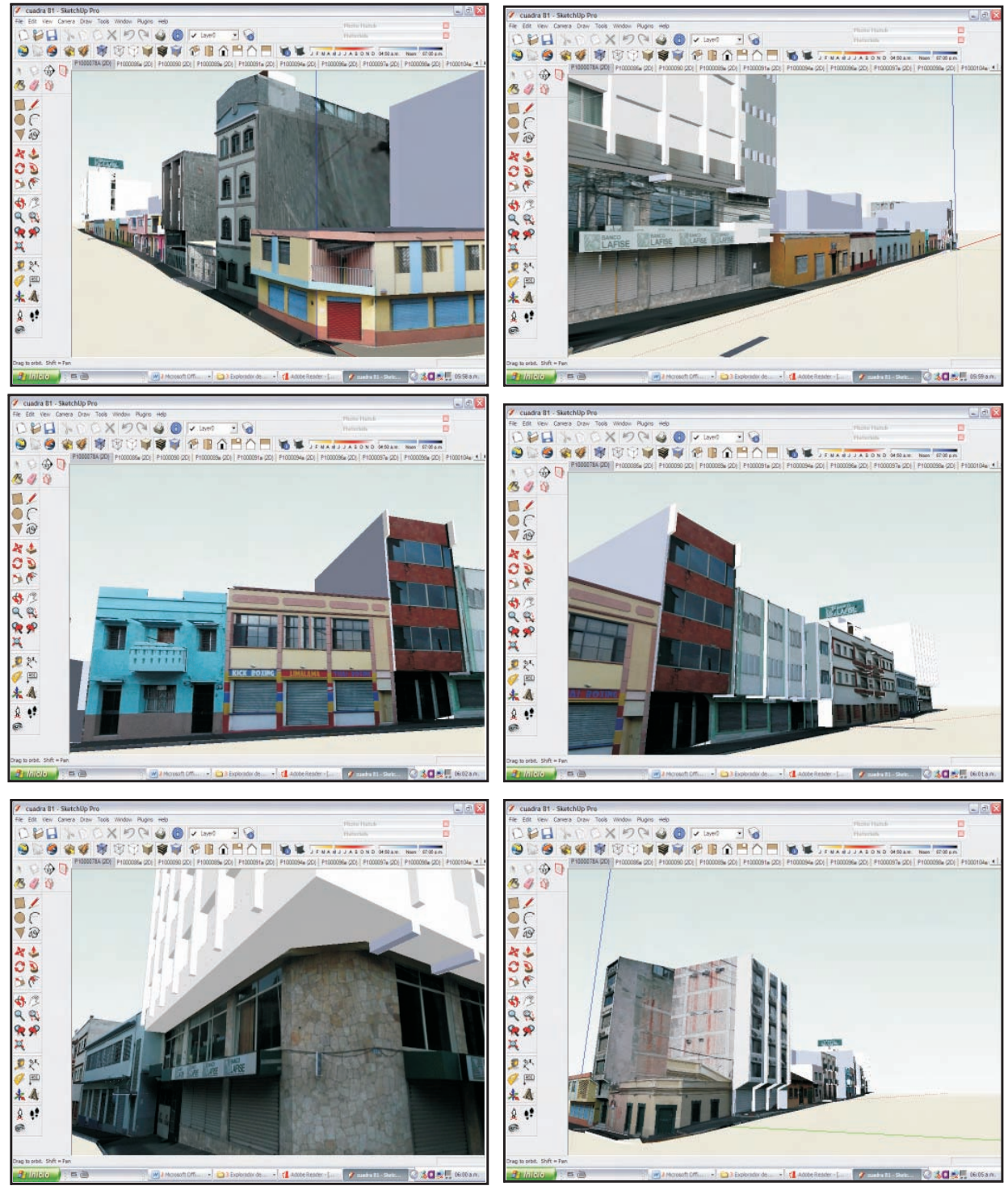

\section{Completado de la escena}

Comprendió la creación y edición de diferentes entornos: desde fondos artificiales con una determinada iluminación, hasta entornos reales construidos en base a modelos de elevación que representan fielmente la orografía del terreno. 
Incorporación de los modelos tridimensionales de edificaciones en el modelo digital del terreno (mdt)

En esta etapa se procedió a exportar los volúmenes 3D de las edificaciones al modelo de terreno desarrollado en el SIG (ver figura 7). Para esto se utilizaron puntos $(X, Y)$ que representan el centroide de ubicación para cada una de ellas, definidas en el sistema de coordenadas en SIG.

\section{Tomas del movimiento y recorridos sobre el modelo}

En esta etapa se procede a definir las rutas del recorrido y ambientación por las diferentes calles proyectadas en el modelo 3D en el SIG; para esto se utilizaron opciones especializadas en el programa de modelado que permite grabar el movimiento y definir rutas. La inmersión en la escena de una cámara virtual y la manipulación de sus diferentes parámetros: focal, eje fotográfico y punto de vista, nos permitirá obtener fotografías virtuales desde cualquier posición en la escena 3D. El fotograma virtual resultante podrá ser almacenado y utilizado en posteriores análisis de perspectiva.

Conversión de los datos geoespaciales en 3D al lenguaje VRML. (Lenguaje de Modelado de Realidad Virtual)

Los datos geoespaciales constituidos por: sistema de coordenadas, nube de puntos, líneas de fuga, entidades geométricas, información de la cámara y metadatos como colores y materiales, fueron automáticamente convertidos al lenguaje VRML exportándolos desde el programa de SIG (Arc Scene) especial para la representación de modelos en 3D.

\section{ANÁLISIS DE LOS DATOS}

\section{Descripción}

El espacio-estudio abarca 11 manzanas situadas desde la parte este de la catedral hasta El Arbolito, en parte del Barrio El Centro y en el barrio La Plazuela, por las avenidas Cervantes, Paz Barahona y Colón y las calles Hipólito Matute, Adolfo Zúniga, Salvador Corleto, Las Damas, Dionisio Gutiérrez, Finlay, Calzada El Arbolito y La Plazuela.

Las manzanas son irregulares debido a la traza original del poblado minero que nunca se estableció en cuadrícula como otras fundaciones hispánicas y a la misma 
topografía del terreno.

El total de los lotes en estas once manzanas es de 112, lógicamente irregulares debido a las divisiones por herencia y venta y en la actualidad al uso comercial que subdivide un mismo lote en varios locales.

El cuadro 1. (ver anexos) muestra cada uno de ellos, según están configurados en el año de 2008, debiéndose advertir que este Centro Histórico tiene mucha dinámica y que son frecuente los cambios de uso en pocos meses del año.

Se hizo una descripción visual del estado actual de las edificaciones comprendidas en el recorrido virtual (avenida Paz Barahona) basada en la documentación de 351 fotografías de 112 inmuebles, la cual se comparó con la descripción de acuerdo al período de clasificación histórica al que perteneció cada edificio. Esta descripción incluye la clasificación de los edificios de acuerdo a tres estilos:

- Temprano

- Intermedio

- Actual

Estos estilos se corresponden con los períodos históricos de esta manera:

- Temprano con los orígenes del primer período, consolidación criolla (segundo período) e independencia (tercer período) o sea desde 1578 a 1880.

- Intermedio corresponde a la reforma liberal(cuarto período) de 1880 a 1950

- Actual con el quinto período de 1950 a la fecha.

\section{Elementos constructivos}

Estilo temprano: el material de construcción es el adobe (bahareque). El zócalo en las fachadas se diferencia por distinto color. Aunque se utilizó bastante el color blanco escalado, también se emplearon colores verdes, ocres, cremas, rojos, azules. Las edificaciones son de un solo piso, rematan en un alero con viga vista y techo de teja. En los interiores de los cuales no vamos a ocuparnos, se utilizaba el tabanco y falso techo. Las puertas son fuertes y de madera, flanqueadas por ventanas; a veces existe además una puerta más ancha o puerta cochera. Las ventanas se cierran con postigos y en la puerta solía haber un cancel. No hay motivos de decoración en las fachadas. 
Edificaciones emblemáticas de este siglo son:

- Edificio público: Iglesia-Convento San Francisco, en particular la iglesia cuya traza data de finales del siglo XVI, siendo el edificio más antiguo de la ciudad.

- Edificio civil: la esquina de la pulpería Chinda Díaz. Obligado referente en el centro de la ciudad.

Estilo intermedio: en 1880, Tegucigalpa fue convertida en capital de la república. Colonias pequeñas pero influyentes de inmigrantes extranjeros se establecen en la ciudad y aportan conceptos que influyen en su aspecto urbanístico, incorporándose a las novedades del momento. En muchas ocasiones más que reconstrucción de edificios se trata de remodelaciones; debido a ello muchos conservan la estructura anterior, por ejemplo su primitivo material de adobes.

Propio de este siglo es el zócalo de ladrillo y almohadillado y sobretodo la supresión de alero con viga vista. Debido a esto, la fachada queda expuesta y comienza a ser decorada, con motivos sencillos y rectilíneos en su remate y luego incorporando volutas y tímpanos con decoración más recargada. Se construyen casas de dos pisos, las ventanas están desprovistas de canceles pero se utiliza el elemento tradicional de las rejas; en el segundo piso se incorporan balcones así mismo enrejados. Las concepciones cívicas de la reforma conducen a establecer parques como lugares de establecimiento y de memoria histórica. No figuran en este espacio construcciones en piedra de cantera que surgen al final de este período.

El estilo intermedio se acomoda al anterior y dado que los limites de la Tegucigalpa tradicional son los de este momento, hasta 1950 ambos estilos coexisten y adquieren un sentido urbanístico unitario que define el perfil del casco histórico.

Edificaciones emblemáticas de este estilo:

- Edificaciones públicas: El PalacioArzobispal.

- Espacio público: El Parque Valle con la estatua de Don José Cecilio del Valle.

- Edificio Civil: el antiguo restaurante Chico Club, que con otro nombre ha conservado aún su función.

Estilo actual: de 1950 en adelante, Honduras y su capital ha experimentado un acelerado crecimiento demográfico. Los viejos limites del Centro Histórico se sobrepasaron por completo, sobre todo al sur y al este de la población. Privó un criterio de modernización sin aportes estilísticos definidos, opuesto a las 
edificaciones tradicionales por considerarlas pueblerinas y de poco valor. Las construcciones son de cemento y de varios pisos, desde 3 ó 4 hasta 100 más, consistentes la mayor parte en bloques superpuestos. Estas edificaciones irrumpen sobre el paisaje tradicional trastocándolo (Véase el edificio Tropi-Gas) aunque recientemente algunas buscan integrarse imitando la construcción tradicional (Banco de los Trabajadores). El deterioro y la desidia de sus propietarios condujo a la perdida de edificios como la casa Midence y en estos casos la sustitución se ha limitado ha transformar el predio en espacio para estacionamiento de vehículos. Los edificios modernos se destinan a locales comerciales y oficinas, sólo rara vez a vivienda. Esto y el traslado de familias del centro hacia otros puntos de la ciudad ha despersonalizado el viejo casco urbano, donde las casas de habitación y las familias avecindadas estaban claramente definidas.

\section{Edificio emblemático de este estilo:}

- Actual Alcaldía Municipal por haber albergado, en sus momentos iniciales a la Escuela Superior del Profesorado.

\section{Valor Histórico}

Prácticamente todas las construcciones en estilo temprano e intermedio poseen valor histórico ya que corresponden al desarrollo urbano de Tegucigalpa tradicional, desde sus orígenes hasta la vísperas de su conversión en urbe moderna. Algunas tienen además un doble valor como la mencionada Iglesia-Convento de San Francisco, Palacio Arzobispal, dada la función importante que vienen realizando a través del tiempo por ser referentes comunitarios, caso de Chinda Díaz y el Chico Club.

De por sí, las construcciones del periodo actual carecen de valor histórico dada su poca calidad estilística y su carencia de arraigo en el paisaje citadino, excepto algún caso como el citado donde funcionó la Escuela Superior del Profesorado.

\section{RESULTADOS}

- En el marco de uno de los principales objetivos del proyecto se creó el modelo de realidad virtual en 3D de una de las zonas más representativas dentro del Centro Histórico del Distrito Central manipulable en tiempo real.

- El vínculo del recorrido virtual a elementos geoespaciales correspondientes en el SIG, constituye uno de los resultados más significativos en el proceso de 
investigación ya que brindará una gran cantidad de posibilidades de análisis en estudio del Centro Histórico con variedad de propósitos.

- La conformación de una base de datos descriptiva y foto ilustrativa de las fachadas y monumentos históricos derivada de la clasificación de los datos recopilados para este proyecto, permitió el análisis comparativo y clasificar las edificaciones de acuerdo a los periodos y estilos arquitectónicos correspondientes a la época histórica.

- Sin duda alguna con este modelo se constituyó una herramienta de investigación del Centro Histórico que además propicie con su metodología el desarrollo de modelos de realidad virtuales con cobertura en el resto del país.

\section{DISCUSIÓN}

Después de analizar nuestro modelo, consideramos que hemos dado un paso al frente en la etapa de la Visualización 3D de los datos Geoespaciales de un área bajo régimen especial como es el Centro Histórico. El enfoque de la investigación que se desarrolló es el de compatibilizar los modelos 3D de simulación de realidad virtual del Centro Histórico con los sistemas de análisis espacial en SIG, con el objetivo de recrear escenarios presentes o futuros ambientados en un espacio real y preciso, con sistemas de análisis del impacto visual, social, económico, histórico y funcional de determinadas actuaciones.

En este sentido, se vislumbra que modelado de realidad virtual vinculado al SIG para la gestión de Centros Históricos brinda una plataforma excelente para el estudio de urbes históricas ya que potenciará la aplicabilidad de las herramientas de análisis y visualización geoespacial .

Con ello se puede afianzar una mejora en la creación y distribución de información de base que actualmente resulta un impedimento significativo; también avanzar en el ordenamiento y gestión de la ciudad existente, realizar propuestas de actuación en las que sea posible integrar criterios sobre las preferencias de los ciudadanos ante determinadas actuaciones o también la representación de normativas de conservación y control dentro de la ciudad.

\section{CONCLUSIONES}

Con este proyecto se pudieron identificar algunas características de las edificaciones que comprende el área de estudio seleccionada y también identificar el contraste de los diferentes estilos que por falta de una normativa de conservación 
histórica arquitectónica ha permitido que el Centro Histórico pierda cierta identidad con respecto los elementos que en la antigüedad lo caracterizaban.

Al generar los modelos mediante procesos de relación de imágenes tomadas en campo versus el catastro municipal (modelo digital) fue posible ver algunas inconsistencia en cuanto a proporción de predios proyectados en el catastro y su medida real por lo que es necesario incluir el proceso de verificación y validación de predios ya catastrados.

La manipulación del modelo en tiempo real ha permitido hacer análisis de perspectiva del Centro Histórico así como captura de detalles arquitectónicos que proporcionen ideas o propuestas de mejoramiento y conservación.

Existen métodos y procedimientos de estudio de la realidad urbana que permiten establecer criterios de diferenciación de la ciudad basadas en datos e información que genera el propio municipio (catastro, actividad económica, censo de población....), la vinculación de bases georeferenciadas de información permite acometer nuevos objetivos cara a la descripción y visualización del espacio urbano a diferentes escalas. Los modelos de visualización en 3D con sus diferentes modelos de representación más detallados o simplemente volumétricos son capaces de presentar una visión cuidada de la realidad urbana.

Sin embargo, es necesario un esfuerzo porque la información referente a una ciudad generada por distintos centros (catastro, gerencia del Centro Histórico, entidad local, empresa de servicios...) sea compartida, como mejora de calidad y optimización de costes de creación y mantenimiento de estas herramientas para el análisis.

\section{AGRADECIMIENTO}

El reconocimiento a aquellas personas que colaboraron en varias etapas técnicas del desarrollo de este proyecto de investigación:

Manuel Hernández, David Duran, Nancy Irías, Elisa Girón, Miguel Sierra.,

A la universidad Nacional Autónoma de Honduras por medio de la Dirección de Investigación Científica por la oportunidad de desarrollar este proyecto en el marco de una beca básica de investigación. 


\section{BIBLIOGRAFÍA}

Caballero L, Pineda M. C. y Moreno E. 2005. Proyecto SIG para la Gestión de Centros Históricos. Honduras: UNAH.

Evans, S, Hudson, A. 2001. "Information Rich 3D Computer Modeling of Urban Environments". Working Paper 35. London: Centre For Advanced Spatial Analysis. University College.

García A, Pilar y Moix B. Montserrat. 2003. "Las tecnologías de visualización urbana SIG 3D y su integración en la internet avanzada, nuevo entorno de estudio de la ciudad". Barcelona: Universidad Politécnica de Cataluña (UPC).

González A. Diego, Gómez L. Javier y Arias P. Benjamín. 2006. "Generación automática de modelos digitales de elevación en VRML" Revista Internacional de Ciencias de la Tierra. Edición especial. 2006.

\section{ANEXOS}

Figura 7. Modelo Digital del Terreno (MDT) del Centro Histórico del Distrito Central

\section{Figura 7. Modelo Digital del Terreno (MDT) del Centro Histórico del Distrito Central}

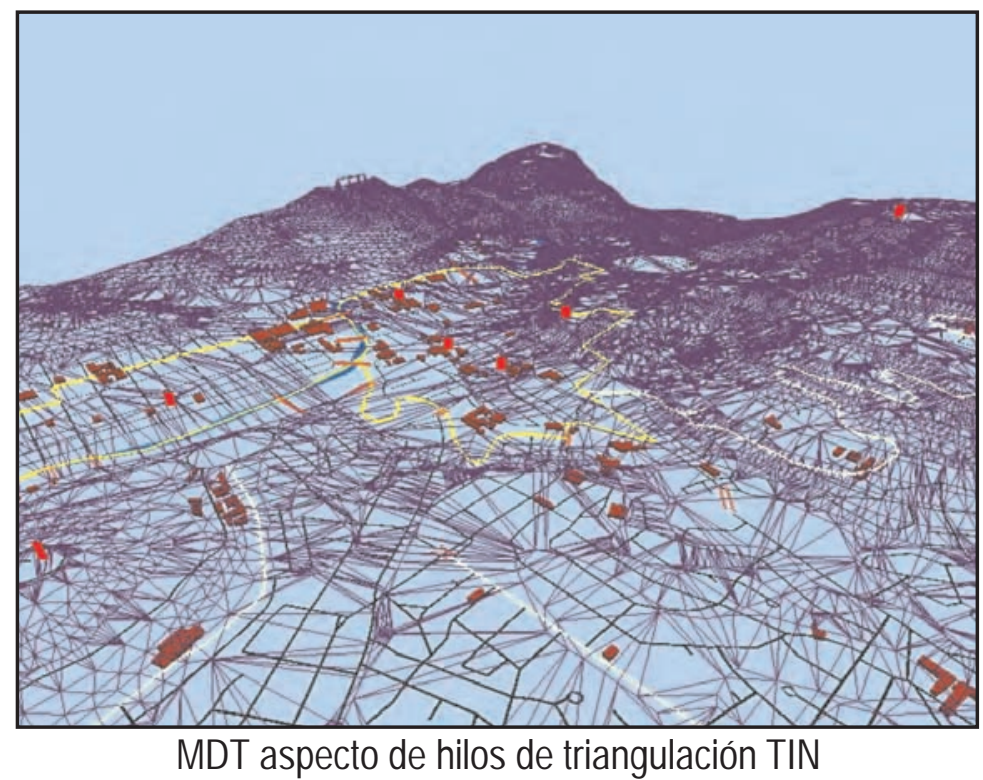




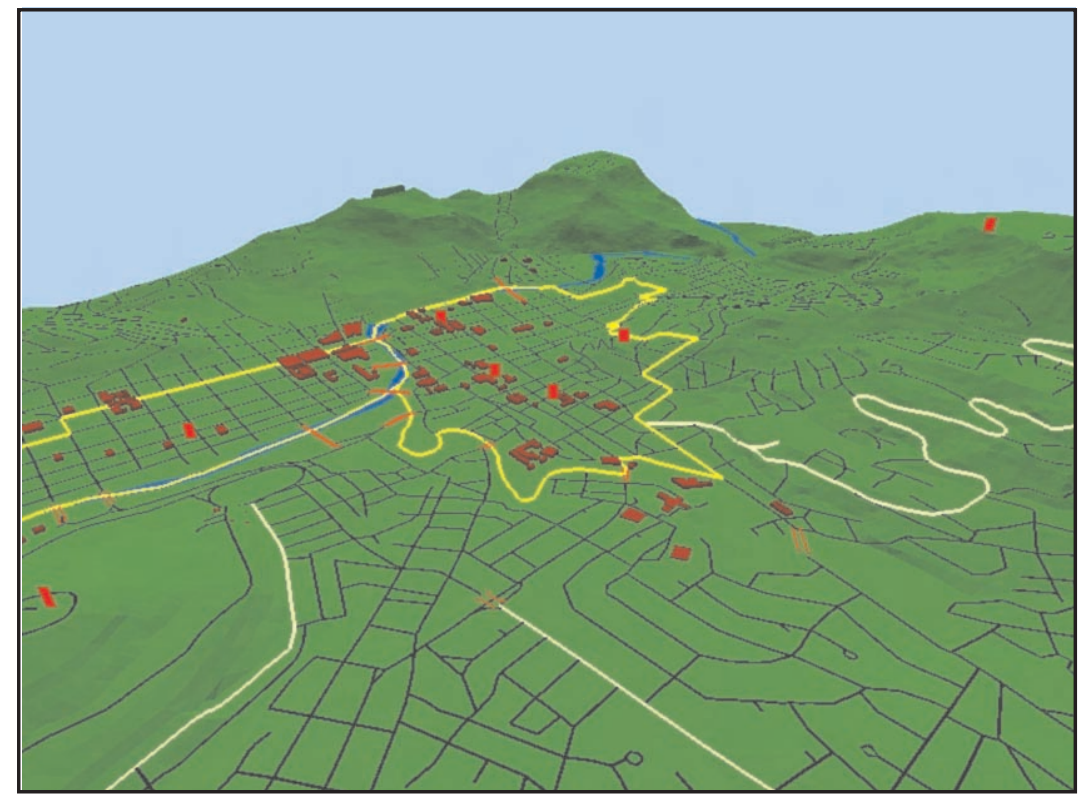

MDT aspecto de polígonos de triangulación TIN

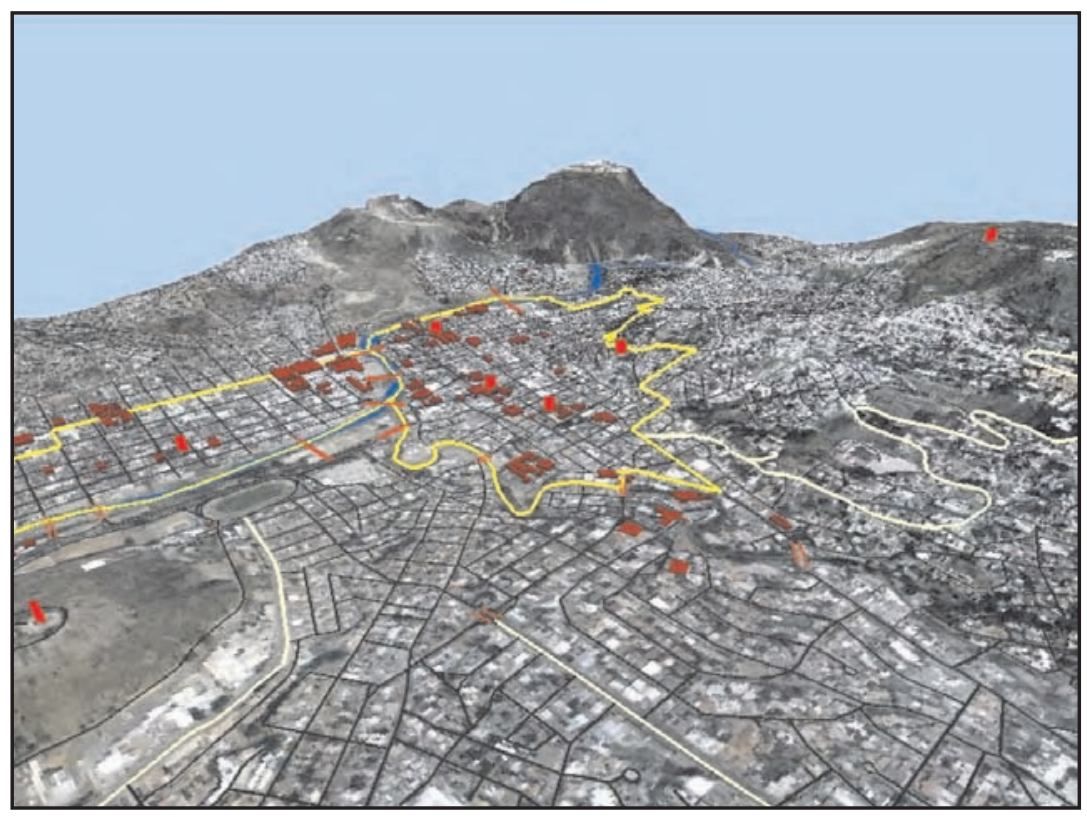

MDT aspecto ortofoto proyectada 